\title{
Binding of protegrin-1 to Pseudomonas aeruginosa and Burkholderia cepacia
}

\author{
Mark T Albrecht ${ }^{1}$, Wei Wang ${ }^{2}$, Olga Shamova ${ }^{2}$, Robert I Lehrer ${ }^{2,3}$ and Neal L Schiller ${ }^{1}$
}

1Division of Biomedical Sciences, University of California, Riverside, California 92521, USA.

2Department of Medicine, University of California, Los Angeles, Los Angeles, California 90095, USA.

3Molecular Biology Institute, University of California, Los Angeles, Los Angeles, California 90095, USA.

Correspondence: Neal L Schiller - neal.schiller@ucr.edu

Received: 1 October 2001

Revisions requested: 19 November 2001

Revisions received: 29 January 2002

Accepted: 31 January 2002

Published: 14 March 2002
Respir Res 2002, 3:18

(C) 2002 Albrecht et al, licencee BioMed Central Ltd

(Print ISSN 1465-9921; Online ISSN 1465-993X)

\begin{abstract}
Background: Pseudomonas aeruginosa and Burkholderia cepacia infections of cystic fibrosis patients' lungs are often resistant to conventional antibiotic therapy. Protegrins are antimicrobial peptides with potent activity against many bacteria, including $P$. aeruginosa. The present study evaluates the correlation between protegrin-1 (PG-1) sensitivity/resistance and protegrin binding in $P$. aeruginosa and $B$. cepacia.

Methods: The PG-1 sensitivity/resistance and PG-1 binding properties of $P$. aeruginosa and $B$. cepacia were assessed using radial diffusion assays, radioiodinated PG-1, and surface plasmon resonance (BiaCore).

Results: The six $P$. aeruginosa strains examined were very sensitive to PG-1, exhibiting minimal active concentrations from $0.0625-0.5 \mu \mathrm{g} / \mathrm{ml}$ in radial diffusion assays. In contrast, all five $B$. cepacia strains examined were greater than 10 -fold to 100 -fold more resistant, with minimal active concentrations ranging from $6-10 \mu \mathrm{g} / \mathrm{ml}$. When incubated with a radioiodinated variant of PG-1, a sensitive $P$. aeruginosa strain bound considerably more protegrin molecules per cell than a resistant $B$. cepacia strain. Binding/diffusion and surface plasmon resonance assays revealed that isolated lipopolysaccharide (LPS) and lipid A from the sensitive P. aeruginosa strains bound PG-1 more effectively than LPS and lipid A from resistant $B$. cepacia strains.

Conclusion: These findings support the hypothesis that the relative resistance of $B$. cepacia to protegrin is due to a reduced number of PG-1 binding sites on the lipid A moiety of its LPS.
\end{abstract}

Keywords: Burkholderia cepacia, lipid A, lipopolysaccharide, protegrin, Pseudomonas aeruginosa

\section{Introduction}

Cystic fibrosis (CF) is a generalized exocrine disease resulting from the defective regulation of epithelial chloride ion transport within various organ systems, most importantly the lungs [1-4]. This dysfunction can arise from a variety of mutations within the cystic fibrosis transmembrane conductance regulator (CFTR) gene on chromosome 7, which encodes the transmembrane pump responsible for regulating transepithelial ion levels $[1,2,4]$. This defect is associated with an increased viscosity of the airway surface fluid, and according to some studies, an altered salt concentra- tion $[5,6]$. These and other pleiotropic effects of the CF gene abnormality increase the susceptibility of CF patients to bronchopulmonary bacterial infection by opportunistic pathogens.

Pseudomonas aeruginosa is the most common pathogen recovered from the lungs of CF patients [2,3]. This predisposition to $P$. aeruginosa infection has been attributed to several factors. For example, an increase in asialo-GM 1 glycoproteins on the apical surface of CF airway epithelial cells provides greater opportunity for adhesion by the type 
IV pili of $P$. aeruginosa[3,7,8]. Furthermore, the first extracellular domain of wild type CFTR has been found to act as a $P$. aeruginosa-specific receptor, which is involved in the clearance of $P$. aeruginosa from the airways via epithelial cell desquamation [9-11], a process greatly impaired in the CF lung. Other conditions that abet colonization of the CF lung include impairment of the "mucociliary escalator" and macrophage-mediated phagocytosis by the viscous airway secretions. If elevated salt concentrations exist within these secretions $[5,6]$, they would inhibit $\alpha$ and $\beta$-defensins, endogenous antibacterial peptides produced by neutrophils and airway epithelia, respectively $[2,3,12-15]$. This last point is still under review as recent evidence suggests that CF airway surface fluid may be isotonic not hypertonic [16].

In recent years Burkholderia cepacia has become the second leading cause of death in patients with chronic granulomatous disease (CGD). The phagocytes of such patients are deficient in their capacity to kill organisms by oxidative means because of a defective NADPH oxidase $[17,18]$. $B$. cepacia also poses a threat to patients with $\mathrm{CF}$, either cocolonizing those already infected with $P$. aeruginosa or as the sole infecting agent $[2,18]$. Although rates of colonization can vary widely (between 5 and $70 \%$ ), B. cepacia is isolated from sputum in only $10 \%-20 \%$ of patients with CF $[2,3]$. B. cepacia, a very diverse species, has been divided into several "classes" of bacteria, i.e., genomovars, collectively referred to as the B. cepacia complex. Genomovar III is the most common $B$. cepacia genomovar isolated from CF patients, accounting for approximately $80 \%$ of $B$. cepacia isolates in CF patients. Genomovars II and V have also been recovered from CF patients [18]. Of critical concern are $B$. cepacia's transmissibility from one patient to another and its propensity to give rise to the $B$. cepacia syndrome, which results in a rapid decline in pulmonary function $[2,18]$. The ability of $B$. cepacia as well as $P$. aeruginosa to cause chronic bronchopulmonary infections in CF patients is exacerbated by their intrinsic or acquired resistance to many conventional antibiotics. Peptide antibiotics, including protegrins, are currently under consideration as novel agents for treating pulmonary infections in CF patients.

Antimicrobial peptides are synthesized either nonribosomally or ribosomally [19]. Protegrin-1 (PG-1), a 2 kDa cationic octadecapeptide (RGGRLCYCRRRFCVCVGR-amide) was originally isolated from porcine leukocytes [20] and falls into the latter category. We selected it for this study because it is rapidly bactericidal, functions well at elevated physiological salt concentrations such as those that may occur in the CF lung, and has a broad spectrum of activity [21-23]. PG-1's antiparallel $\beta$-hairpin structure and antimicrobial activity in physiological and elevated salt concentrations are maintained by its two intramolecular cystine disulfide bonds $[21,24-28]$. The antimicrobial spectrum of
PG-1 includes Chlamydia trachomatis, Candida albicans, Escherichia coli, Fusobacterium nucleatum, Haemophilus ducreyi, Listeria monocytogenes, Neisseria gonorrhoeae, Porphyromonas gingivalis, Prevotella intermedia, P. aeruginosa, and Staphylococcus aureus[20,22,25,29-32].

This study tested the hypothesis that the relative sensitivity or resistance of $P$. aeruginosa and $B$. cepacia strains to PG-1 correlates to the extent of peptide binding. A previously described two-stage radial diffusion technique designed for peptide antibiotics was used to determine susceptibility. Binding of protegrins to intact $P$. aeruginosa and $B$. cepacia cells and to purified lipopolysaccharide (LPS) and lipid A prepared from these organisms was measured by three different techniques.

\section{Materials and methods \\ Bacterial strains and growth media}

Two sets of genetically related $P$. aeruginosa strains were studied. Strain $144 \mathrm{M}$, a serum-sensitive mucoid isolate from a CF patient, contains short O-side chain LPS, while its serum-resistant derivative, $144 \mathrm{M}(\mathrm{SR})$, which is also mucoid, has long O-side chain LPS [33]. Strain FRD-1 is a mucoid CF isolate [34] and FRD-2 is its spontaneous nonmucoid derivative [35]. $P$. aeruginosa ATCC strains 10145 and 9027 are nonmucoid strains with long O-side chain LPSs [N L Schiller, unpublished results]. We also studied B. cepacia ATCC strains 25416 and 25609, as well as three clinical strains isolated from patients with CF in Vancouver, Canada, kindly provided by David P Speert, University of British Columbia. These strains included: C4813, genomovar IIla, B. cepacia epidemic strain marker (BCESM) positive, cable pilin subunit gene A (cable A) negative; $\mathrm{C} 4878$, genomovar Illa, BCESM positive, cable $A$ negative; and C6159, genomovar Illb, BCESM and cable A negative. BCESM and cable $A$ are putative transmissibility markers [36]. Log-phase cultures were grown at $37^{\circ} \mathrm{C}$ with shaking in trypticase soy broth (TSB) (Becton-Dickinson Microbiology, Cockeysville, MD).

\section{Protegrin}

PG-1 was prepared as previously described [25] and was approximately $96.5 \%$ pure. PG-1 was dissolved in and diluted with filter-sterilized acidified water $(0.01 \%$ acetic acid) supplemented with $0.1 \%$ human serum albumin (Sigma, St. Louis, MO). The albumin in the PG-1 vehicle helped reduce nonspecific adsorption of protegrins when the stock solutions were serially diluted $[22,37]$. These PG-1 stock solutions were filter-sterilized prior to storage at either $-20^{\circ} \mathrm{C}$ for short term ( $<3$ months) or $-80^{\circ} \mathrm{C}$ for long-term storage.

\section{Radial diffusion assay}

The two-stage radial diffusion assay protocol as described by Steinberg and Lehrer [37] and Lehrer et al. [38] was al- 
tered by supplementing the underlay agar with $150 \mathrm{mM}$ $\mathrm{NaCl}$ to ascertain PG-1's ability to kill $P$. aeruginosa and $B$. cepacia at an elevated salt concentration. These assays were interpreted as described below. The sample wells received $5 \mu$ of PG-1 (various concentrations) or its vehicle. We analyzed the radial diffusion assay results in two ways. In one, we calculated the lethal concentration $\left(\mathrm{C}_{\mathrm{L}}\right)$ as described by Hultmark et al. $[39,40]$ from wells surrounded by net clear zones of 1 to $2.5 \mathrm{~mm}$. In the other, we defined the minimal active concentration (MAC) as the lowest concentration of PG-1 that produced a measurable, totally clear, inhibition zone around the well.

\section{Whole cell binding assay}

Binding of PG-1 to intact cells was measured with a monoradioiodinated variant of $P G-1$. This protegrin variant differed from PG-1 in two ways: Phe7 replaced Tyr7 in the protegrin domain, and an N-terminal glycine-rich hexapeptide extension (GGGYGG) with a single tyrosine residue was present. In this report the modified peptide and its monoiodinated variant will be called "GGPG" and "I-GGPG", respectively. The full sequence of GGPG is GGGYGGRGGRLCFCRRRFCVCVGR-CONH${ }_{2}$. In preliminary experiments, we determined that PG-1, GGPG, and I-GGPG exhibited virtually identical antimicrobial potency and kinetics (data not shown).

GGPG was iodinated with $\mathrm{Nal}$ or $\mathrm{Na}^{125}$ (Pierce, Rockford, IL) by the iodobead method $[41,42]$. Unincorporated Nal or $\mathrm{Na}^{125}$ was removed by solid phase extraction on a SepPak C-18 Plus Cartridge. I-GGPG was purified from uniodinated and di-iodinated GGPG by reverse phase-HPLC (Vydac, Hesperia, CA). Binding assays were done with stationary phase $P$. aeruginosa 9027 or B. cepacia 25416, both typically at $2.5 \times 10^{7} \mathrm{CFU} / \mathrm{ml}$. The bacteria were incubated with ${ }^{125}$-GGPG at $0^{\circ} \mathrm{C}$ for $60 \mathrm{~min}$ at $\mathrm{pH} 7.4$ in a 10 $\mathrm{mM}$ Tris-acetate buffer containing $100 \mathrm{mM} \mathrm{NaCl}, 1 \% \mathrm{TSB}$, and $1 \%$ BSA. Samples were layered over $0.3 \mathrm{ml}$ of a cushion composed of 5 parts of dibutyl phthalate and 3 parts of di-isodecyl phthalate (density ${ }_{20}=1.01$ ) and centrifuged at approximately $14,000 \times g$. After removing the supernatant and phthalate oil, the base of the tube was severed with a razor blade and the stub, which contained the pellet, was recovered for radioactivity counting.

\section{LPS and lipid $A$ extraction and analysis}

Bacterial LPS was isolated according to the protocol of Darveau and Hancock [43] with some modifications, as described below. Strains were grown overnight in TSB, collected via centrifugation $\left(10,000 \times g\right.$ for $20 \mathrm{~min}$ at $\left.0^{\circ} \mathrm{C}\right)$, and suspended in a $\mathrm{pH} 8.0$ buffer $(5.0 \mathrm{~g}$ of wet weight bacteria/30 $\mathrm{ml}$ of buffer) that contained $10 \mathrm{mM}$ Tris-hydrochloride, $2 \mathrm{mM} \mathrm{MgCl} 2,100 \mu \mathrm{g} / \mathrm{ml}$ DNase I, and $25 \mu \mathrm{g} / \mathrm{ml}$ RNase I. The slurry was passed twice through a French Press set at 20,000 lbs/in². DNase and RNase were again added, and the mixture was incubated at $37^{\circ} \mathrm{C}$ for 2 hours. Then, to each $15 \mathrm{ml}$ of suspension, the following were added: $5.0 \mathrm{ml}$ of $0.5 \mathrm{M}$ tetrasodium EDTA in $10 \mathrm{mM}$ Tris buffer, $2.5 \mathrm{ml}$ of $20 \%$ SDS in $10 \mathrm{mM}$ Tris buffer, and $2.5 \mathrm{ml}$ of 10 $\mathrm{mM}$ Tris buffer. The preparation was mixed and centrifuged at $50,000 \times g$ for $30 \mathrm{~min}$ at $20^{\circ} \mathrm{C}$ to remove the peptidoglycan. Protease (Sigma P5147) at $200 \mu \mathrm{g} / \mathrm{ml}$ was added to the supernatant and incubated at $37^{\circ} \mathrm{C}$ overnight with agitation. On the next day, $0.375 \mathrm{M} \mathrm{MgCl}_{2}$ in $95 \%$ ethanol was added and the suspension was cooled to $0^{\circ} \mathrm{C}$ before centrifugation at $12,000 \times g$ for $15 \mathrm{~min}$ at $0^{\circ} \mathrm{C}$. The resulting pellet was resuspended in $2 \%$ SDS, $0.1 \mathrm{M}$ tetrasodium EDTA in $10 \mathrm{mM}$ Tris buffer and sonicated. This solution was incubated at $85^{\circ} \mathrm{C}$ for $30 \mathrm{~min}$, and cooled to room temperature before protease $(25 \mu \mathrm{g} / \mathrm{ml})$ was added and incubated overnight at $37^{\circ} \mathrm{C}$. After re-precipitation the following day with ethanol, the pellet was resuspended in $10 \mathrm{mM}$ Tris buffer and centrifuged at $200,000 \times g$ for 2 hours at $20^{\circ} \mathrm{C}$ in the presence of $25 \mathrm{mM} \mathrm{MgCl}_{2}$. The final LPS extract was suspended in $10 \mathrm{ml} \mathrm{dH_{2 }} \mathrm{O}$ and dialyzed overnight against $\mathrm{dH}_{2} \mathrm{O}$ to remove any residual salt and SDS prior to being lyophilized. Contamination of the LPS samples by protein represented no more than $3.6 \% \pm 0.21 \%$, as estimated by measuring the dry weight and protein concentration with the Bio-Rad Protein Assay Kit. Nucleic acid contamination was considered to be minimal due to the repeated DNase and RNase treatments. LPS preparations were diluted using the PG-1 vehicle prior to assaying with PG-1.

Lipid A was extracted from isolated LPS preparations via acid hydrolysis $[44,45]$. Isolated LPS $(25-30 \mathrm{mg})$ was suspended in $4 \mathrm{ml}$ of a $1 \%$ acetic acid solution and heated in a water bath to $100^{\circ} \mathrm{C}$ under refluxing conditions for 3 hours. Once the lipid A was hydrolyzed, it precipitated out of solution and was extracted with five sequential $4 \mathrm{ml}$ aliquots of chloroform. Lipid A extracts were collected and washed three times with $10 \mathrm{ml}$ aliquots of $\mathrm{dH}_{2} \mathrm{O}$ before being lyophilized. Lipid A was dissolved in 100\% dimethyl sulfoxide (DMSO), which was diluted to $2.5 \%$ with the PG-1 vehicle before application in the radial diffusion assay.

In order to measure the ability of LPS and lipid A to bind PG-1, we modified the two stage radial diffusion assay so that we could ascertain the amount of LPS or lipid A (in ng), that reduced the antimicrobial activity of $50 \mathrm{ng}$ of PG-1 by 50 percent (called the effective concentration $50 \%$ or $\mathrm{EC}_{50}$ ). Briefly, $2.5 \mu \mathrm{l}$ of a $20 \mu \mathrm{g} / \mathrm{ml} \mathrm{PG}-1$ solution and 2.5 $\mu$ l of LPS or lipid A (at various concentrations based on their dry weight) were combined, and added to the radial diffusion wells. After a 3-hour incubation, a nutrient rich overlay gel was poured and the plates were incubated overnight. The following day, zone diameters (including the wells) were measured in $\mathrm{mm}$. Since the height (h) of the underlay gel was always $1.2 \mathrm{~mm}$, the zone diameters were converted to volumes cleared of viable bacteria with the for- 
mula for the volume of a cylinder: $V=\pi r^{2} h$. Since the $3 \mathrm{~mm}$ diameter sample well was devoid of both bacteria and peptide, its volume $(8.5 \mu \mathrm{l})$ was subtracted from the gross clear zone volume $\left(\pi r^{2} h\right)$ to derive the net volume rendered free of bacteria. As will be shown below, this net volume was a linear function of the amount of PG-1 placed in the well, for amounts of protegrin between $0-50 \mathrm{ng} /$ well.

\section{Surface plasmon resonance}

Binding of LPS or lipid A to PG-1 was assessed with a Biacore 2000 system (BiaCore AB, Piscataway, NJ); a very similar approach was used to study LPS binding by peptide domains of horseshoe crab factor $C$ [46]. This innovative technology uses surface plasmon resonance to study biomolecular interactions in real time. Briefly, the binding takes place on a small chip coated with a thin layer of metal. It is monitored by monochromatic, p-polarized light whose electric vector component is parallel to the plane of incidence. Under these conditions, the intensity of the reflected light is markedly reduced at a specific incident angle, producing a sharp "shadow". This phenomenon is called "surface plasmon resonance" (SPR) and the incident light angle at which the shadow is observed is the "SPR angle". Detection of the SPR angle depends on changes in the refractive index (RI) of the medium on the nonilluminated side of the chip. Since this RI depends on the mass concentration of macromolecules at this surface, monitoring the SPR angle provides a real-time measure of changes in the surface concentration. The SPR spectrum is a plot of the SPR angle against time, and displays the interaction's progress at the sensor surface. The SPR signal is expressed in resonance units (RU), and $1000 \mathrm{RU}$ is equivalent to a change in surface protein concentration of about $1 \mathrm{ng} / \mathrm{mm}^{2}$ or of about $6 \mathrm{mg} / \mathrm{ml}$ in the bulk protein concentration.

In our study, LPS and lipid A samples from $P$. aeruginosa 9027 and $B$. cepacia 25416 were immobilized on a hydrophobic HPA sensor chip (BR-1000-30, Biacore AB) that was found, in our preliminary experiments, to provide an optimal matrix for LPS and lipid A. The surface of HPA sensor chips is composed of long-chain alkanethiol molecules that form a flat, quasi-crystalline hydrophobic layer that facilitates hydrophobic adsorption of liposomes or micelles on a user-defined polar lipid monolayer. The chip was precleaned and conditioned by washing twice with $40 \mathrm{mM} \mathrm{n-}$ octyl glucoside (Sigma Chemical Co.). To immobilize the LPS, $60 \mu \mathrm{l}$ of a $1 \mathrm{mg} / \mathrm{ml}$ LPS preparation was dispersed in $100 \mathrm{mM} \mathrm{NaCl}$ containing $10 \mathrm{mM}$ HEPES buffer (pH 7.4), and passed across the chip's surface for $30 \mathrm{~min}$, at flow rate of $2 \mu \mathrm{l} / \mathrm{min}$. Lipid A was dissolved and immobilized similarly, except that its concentration was reduced to $0.2 \mathrm{mg} /$ $\mathrm{ml}$. Residual unbound LPS and lipid $A$ were washed away with $0.1 \mathrm{M} \mathrm{HCl}$ and $0.1 \mathrm{M} \mathrm{NaOH}$. BSA $(0.1 \mathrm{mg} / \mathrm{ml})$ was used to detect nonspecific binding on the surfaces coated by LPS or lipid A. PG-1 binding was measured by observ- ing the change in the SPR angle of the sample bound to the chip as $30 \mu \mathrm{l}$ of PG-1 $(20 \mu \mathrm{M}, 10 \mu \mathrm{M}, 6 \mu \mathrm{M}, 3 \mu \mathrm{M}, 2 \mu \mathrm{M}$, and $1 \mu \mathrm{M}$ ) flowed over the sample for $3 \mathrm{~min}$ at a rate of 10 $\mu \mathrm{l} / \mathrm{min}$. These PG-1 solutions were also prepared in 100 $\mathrm{mM} \mathrm{NaCl}$ containing $10 \mathrm{mM}$ HEPES buffer ( $\mathrm{pH}$ 7.4). Each binding study was done in triplicate and the chip was regenerated between trials by washing it with $0.1 \mathrm{M} \mathrm{HCl}$ and $0.1 \mathrm{M} \mathrm{NaOH}$.

\section{Results}

Activity of PG-1 on $P$. aeruginosa and $B$. cepacia strains The $C_{L}$ and MAC for PG-1 on $P$. aeruginosa and $B$. cepacia were determined in two-stage radial diffusion assays (Table 1). The mean $\mathrm{C}_{\mathrm{L}}$ of $\mathrm{PG}-1$ for the six $P$. aeruginosa strains was $0.30 \mu \mathrm{g} / \mathrm{ml}$, and the mean $C_{\mathrm{L}}$ for the five $B$. cepacia strains was $5.02 \mu \mathrm{g} / \mathrm{ml}$, a 16.7 -fold difference. The mean MACs for $P$. aeruginosa and $B$. cepacia were 0.17 $\mu \mathrm{g} / \mathrm{ml}$ and $8.40 \mu \mathrm{g} / \mathrm{ml}$, respectively. The $C_{L}$ and MAC values for $P$. aeruginosa and $B$. cepacia differed significantly ( $P$ exact $=0.004)$ when the data were analyzed by the Mann-Whitney test.

We also compared two sets of genetically related $P$. aeruginosa strains: 144M/144M(SR) and FRD-1/FRD-2. Whereas the LPS of strain $144 \mathrm{M}$ has a very short O-antigen side chain, LPS from strain $144 \mathrm{M}(\mathrm{SR})$ has a very long $\mathrm{O}$-antigen side chain. However, despite these differences both strains had comparable $C_{L}$ and $M A C$ values. Similarly, comparison of the alginate producer FRD-1 with FRD-2, its spontaneous nonmucoid derivative, revealed that both strains had very similar $C_{L}$ and MAC values.

\section{Intact/whole cell binding}

Incubation of 125 I-GGPG with intact $P$. aeruginosa 9027 (PG-1 sensitive) and $B$. cepacia 25416 (PG-1 resistant) cells demonstrated a marked difference in protegrin binding between the two strains (Fig. 1). When the bacteria were exposed to $12.5 \mu \mathrm{g}$ 125/-GGPG /ml, approximately sixfold more protegrin molecules bound to $P$. aeruginosa than to $B$. cepacia, and at an 125/-GGPG concentration of $25 \mu \mathrm{g} / \mathrm{ml}, 12$ times as many protegrin molecules bound to $P$. aeruginosa. Another factor also merits mention in this regard. By light microscopy, the $B$. cepacia cells appeared larger than the $P$. aeruginosa cells. By electron microscopy, we found that the mean cross sectional diameters and lengths of $B$. cepacia 25416 cells were $0.755 \mu \mathrm{m} \times 2.55$ $\mu \mathrm{m}$. The corresponding values for $P$. aeruginosa 9027 cells were $0.615 \mu \mathrm{m} \times 2.35 \mu \mathrm{m}$. Assuming a cylindrical structure for both, we calculated that the surface area of the $B$. cepacia cells $\left(6.00 \mu \mathrm{m}^{2}\right)$ was approximately $33 \%$ larger on average than that of $P$. aeruginosa $\left(4.54 \mu \mathrm{m}^{2}\right)$.

\section{Binding of PG-1 to LPS and lipid $A$}

To compare binding of PG-1 to LPS and lipid A from $P$. aeruginosa 9027 and B. cepacia 25416, we devised a simple 


\section{$C_{L}$ and MAC values for various $P$. aeruginosa and $B$. cepacia strains determined using the radial diffusion assay.}

\begin{tabular}{|c|c|c|c|c|}
\hline Organism & Strain & Comments & $C_{L}{ }^{*}$ & MAC $^{*}$ \\
\hline$P$. aeruginosa & $144 \mathrm{M}$ & Serum sensitive, mucoid, short chain LPS & 0.20 & 0.0625 \\
\hline$P$. aeruginosa & $144 \mathrm{M}$ (SR) & Serum resistant, mucoid, long chain LPS & 0.18 & 0.0625 \\
\hline$P$. aeruginosa & FRD-1 & Mucoid strain & 0.15 & 0.125 \\
\hline$P$. aeruginosa & FRD-2 & Nonmucoid strain & 0.19 & 0.125 \\
\hline$P$. aeruginosa & 10145 & ATCC strain & 0.25 & 0.125 \\
\hline$P$. aeruginosa & 9027 & ATCC strain & 0.81 & 0.50 \\
\hline Mean \pm SEM & (all 6 strains) & & $0.30 \pm 0.10^{\star *}$ & $0.17 \pm 0.07^{\star \star}$ \\
\hline B. cepacia & C6159 & Clinical isolate & 1.35 & 6 \\
\hline B. cepacia & C4813 & Clinical isolate & 5.70 & 8 \\
\hline B. cepacia & C4878 & Clinical isolate & 1.53 & 8 \\
\hline B. cepacia & 25416 & ATCC strain & 7.57 & 10 \\
\hline B. cepacia & 25609 & ATCC strain & 8.95 & 10 \\
\hline Mean \pm SEM & (all 5 strains) & & $5.02 \pm 1.55^{\star *}$ & $8.40 \pm 0.75^{\star *}$ \\
\hline
\end{tabular}

${ }^{\star}$ Each value represents the mean of three replicate assays, shown in $\mu \mathrm{g} / \mathrm{ml} .{ }^{* *}$ Mann-Whitney test, $P$. aeruginosa versus $B$. cepacia, $P$ exact for $C_{\mathrm{L}}=$ $0.004, \mathrm{MAC}=0.004$.

\section{Figure 1}

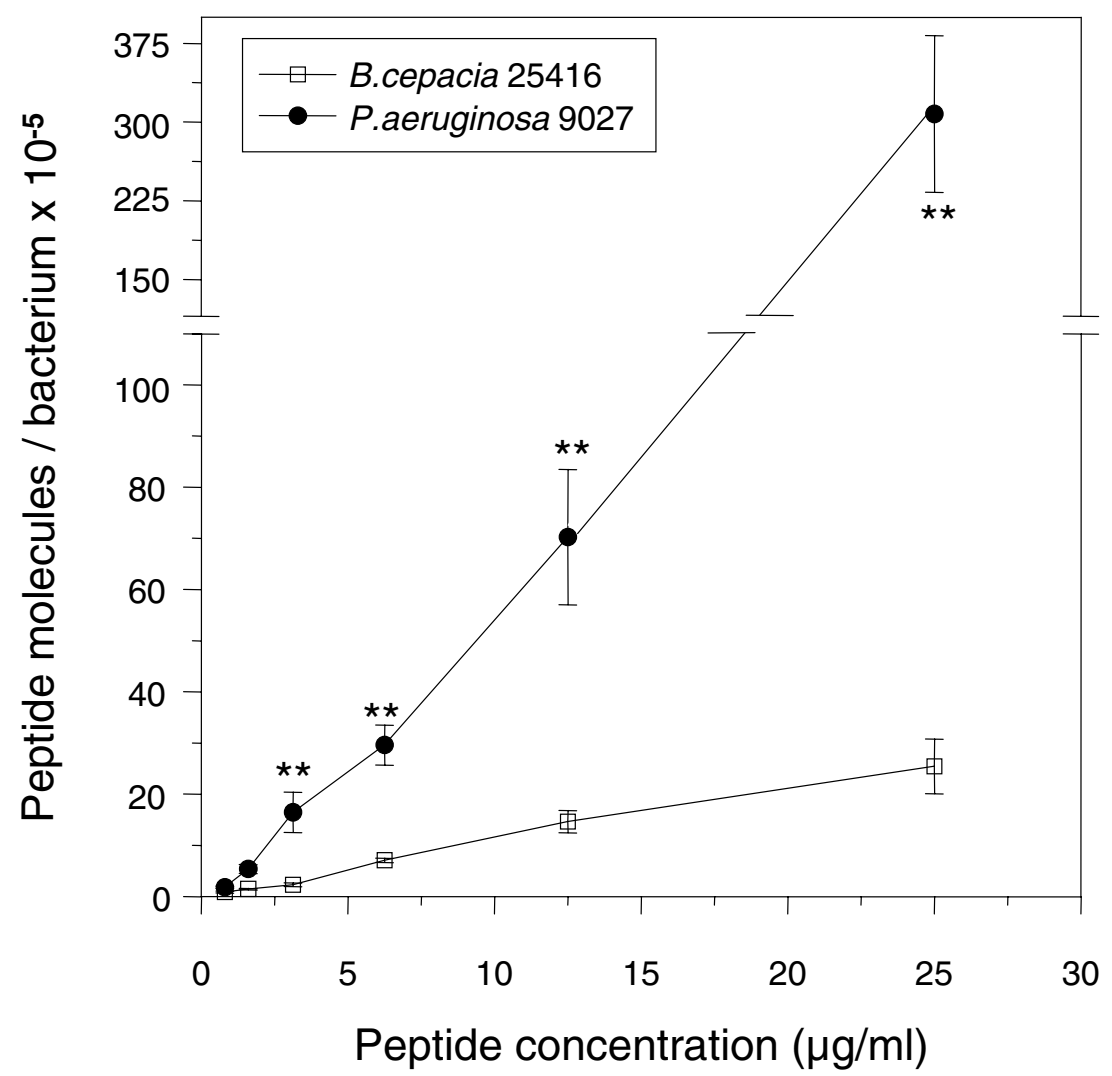

Binding of 125 -GGPG. Stationary phase bacteria, $2.5 \times 10^{7} \mathrm{CFU} / \mathrm{ml}$, were incubated with the indicated concentrations of I125-GGPG for 60 min at $0{ }^{\circ} \mathrm{C}$, and centrifuged through a phthalate ester "cushion" to separate free and bound peptides. The data points are mean \pm SEM values from 5 to 9 replicates obtained in three separate experiments. Using the Mann-Whitney test, $P$ was $<0.05$ at values indicated by ${ }^{* *}$. 


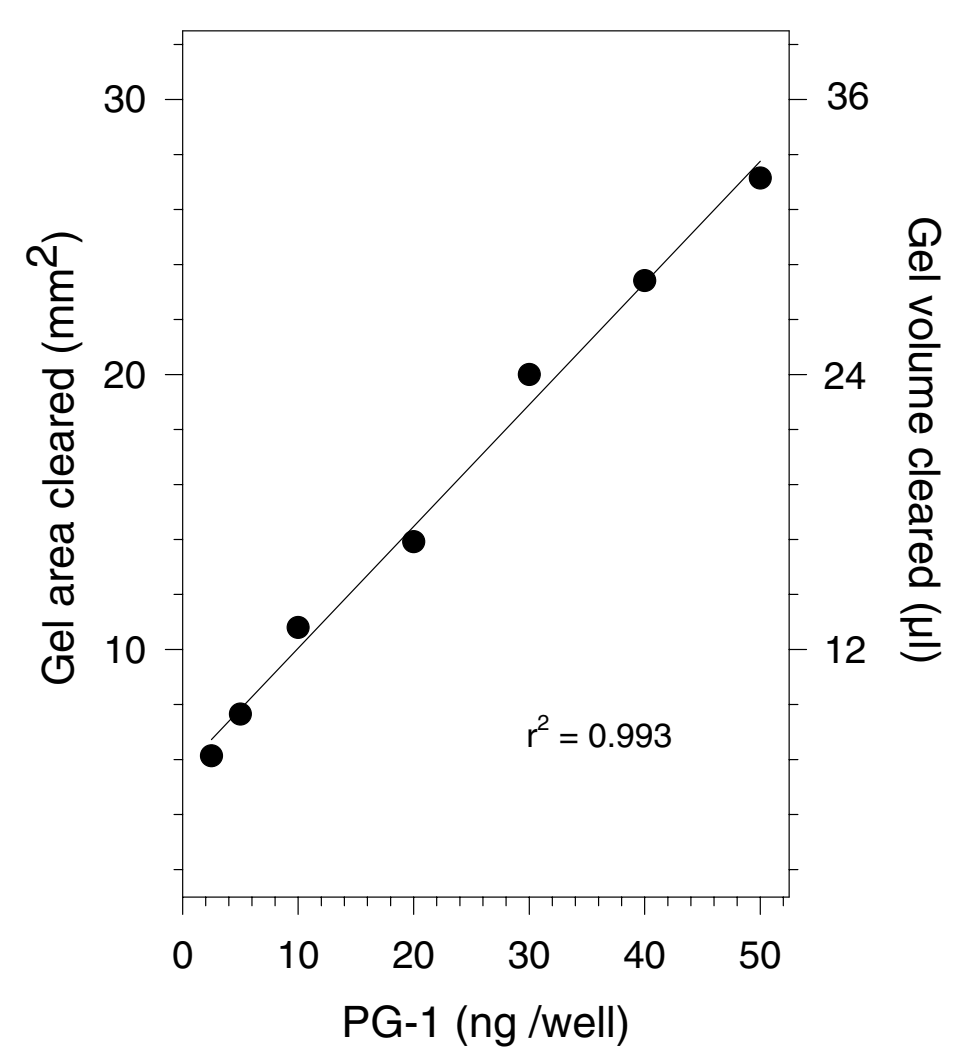

Quantitative aspects of PG-1 mediated killing measured by two-stage radial diffusion assays. The left ordinate scale shows the net area of underlay gel totally cleared of viable bacteria using the equation $\left(\pi d^{2}-9\right) \div 4$, where $d$ is the diameter of the cleared zone including the well diameter and 9 is subtracted to account for the area of the well, which is devoid of bacteria. The right ordinate scale shows the volume cleared (area cleared times the height of the underlay gel, $1.2 \mathrm{~mm})$. All data points are means $(n=3)$. Note that $Y$ is a linear function of $X$ for these peptide concentrations. Area (A) and volume $(\mathrm{V})$ are related by the equation: $\mathrm{A}\left(\mathrm{mm}^{2}\right)=\mathrm{V}(\mu \mathrm{l}) / 1.2 \mathrm{~mm}$.

bioassay based on the radial diffusion assay. As shown in Fig. 2, for protegrin amounts between 0 and $50 \mathrm{ng}$, the volume of underlay gel that was rendered completely free of viable bacteria was linearly related to the amount of peptide introduced into the well. By mixing a constant amount of protegrin (within this linear range) with graded amounts of purified LPS and lipid A, we could readily determine how much of these ligands were needed to reduce the activity of $50 \mathrm{ng}$ of PG- 1 by $50 \%$ (the $\mathrm{EC}_{50}$ values). The results of our assays with LPS and lipid A purified from the strains we used in the above 125I-GGPG binding studies are shown in Fig. 3A. The $E_{50}$ values for LPS isolated from $P$. aeruginosa and $B$. cepacia differed by 4.6 -fold (100 ng versus $460 \mathrm{ng}$ ) while the $E_{50}$ values for lipid $A$ isolated from the same strains differed by approximately 16.7-fold (60 $\mathrm{ng}$ versus $1000 \mathrm{ng}$ ).

To ascertain if these findings were representative, we prepared LPS and lipid A from another pair of bacteria $(P$. aer- uginosa FRD-2 and B. cepacia C4813) and repeated the studies. The $\mathrm{EC}_{50}$ values for both LPS and lipid $A$ obtained from $P$. aeruginosa FRD-2 were each $120 \mathrm{ng}$. The values for $B$. cepacia LPS and lipid A were estimated as approximately $2050 \mathrm{ng}$ for both (Fig. 3B), a difference of 17.1 -fold when compared to $P$. aeruginosa FRD-2 LPS and lipid A.

\section{Surface plasmon resonance studies}

We also used SPR spectroscopy to compare the binding of PG-1 to LPS and lipid A purified from $P$. aeruginosa 9027 and B. cepacia 25416. Injection of LPS or lipid A from both strains was stopped when the increase in RU of both reached 1000. Loosely bound molecules were washed away by increasing the flow rate to $100 \mu \mathrm{l} / \mathrm{min}$, followed by two, one-minute short pulse injections of $100 \mathrm{mM}$ $\mathrm{NaOH}$. Injections of $0.1 \mathrm{mg} / \mathrm{ml} \mathrm{BSA}$ prepared in the eluent buffer were passed across the LPS or lipid A coated surfaces for a five-minute period and showed an increase of around $100 \mathrm{RU}$, whereas the same amount of BSA passed 


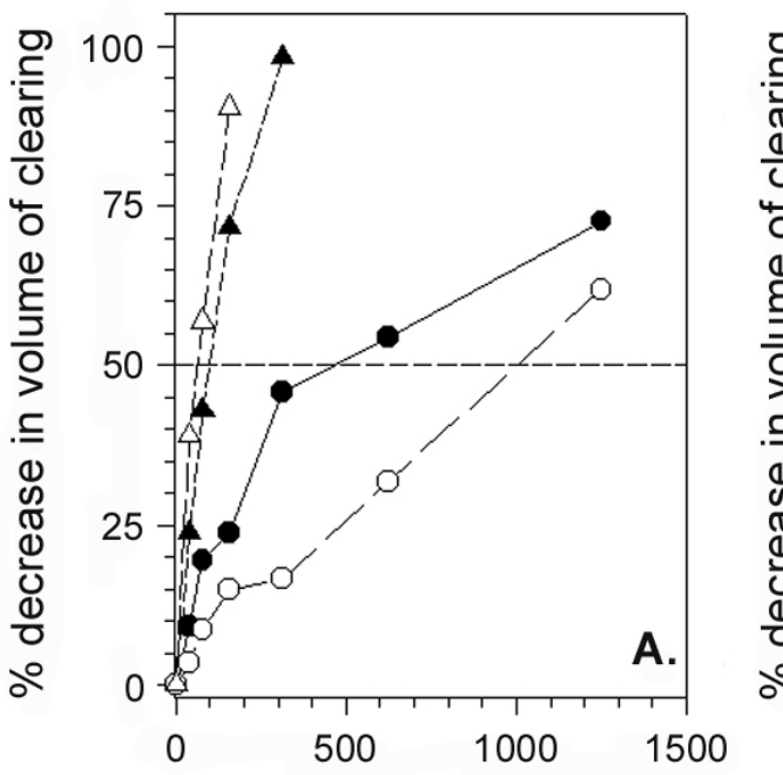

Lipid A or LPS (ng/well)

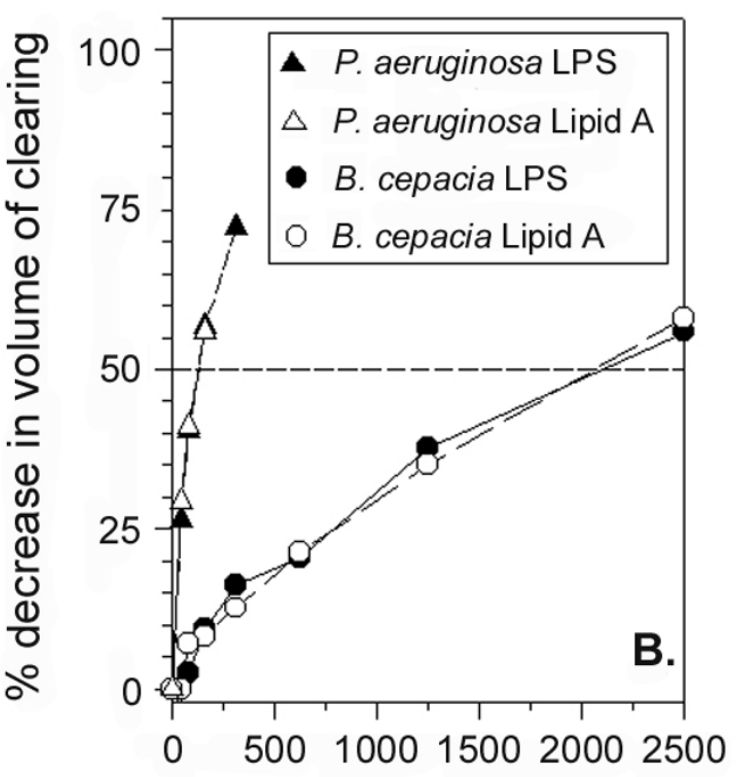

Lipid A or LPS (ng/well)

Binding of PG-1 to LPS and lipid A. Binding/radial diffusion assays were conducted by mixing various amounts of LPS or lipid A with 50 ng of PG-1 in a final volume of $5 \mu \mathrm{l}$. In Panel A, the LPS and lipid A preparations were isolated from $P$. aeruginosa strain 9027 and $B$. cepacia strain 25416 . In Panel B, the LPS and lipid A were isolated from P. aeruginosa FRD-2 and B. cepacia C4813. The mixtures of PG-1 with LPS or lipid A were introduced into the wells of radial diffusion assay plates seeded with $P$. aeruginosa FRD-1, a highly susceptible test organism. All data points are means $(n=3)$, and $\mathrm{EC}_{50}$ values were extrapolated from these graphs. When these binding isotherms were subjected to linear regression analysis, the $95 \%$ confidence limits of the LPS and lipid A binding isotherms for $P$. aeruginosa and $B$. cepacia were non-overlapping, and the isotherms for the LPS preparations in Panel A overlapped only at the lowest ligand concentrations (data not shown).

across the uncoated, n-octyl glucoside washed surface showed an increase of roughly $1000 \mathrm{RU}$. This demonstrated that the surface of the chip was fully covered by LPS or lipid A. Since similar amounts of these ligands had bound to the chip, the response unit differences seen at concentrations between 1 and $20 \mu \mathrm{M}$ indicate that approximately twice as much PG-1 bound $P$. aeruginosa lipid $A$ as bound lipid A from the B. cepacia strain (Fig. 4). Binding differences were less marked when we studied LPS from these organisms (Fig. 5). Although up to one third more protegrin molecules bound to $P$. aeruginosa LPS than to $B$. cepacia LPS at protegrin concentrations of 1-6 $\mu \mathrm{M}$, these differences disappeared when we tested higher PG-1 concentrations. At $10 \mu \mathrm{M}$ PG-1, LPS from $P$. aeruginosa and $B$. cepacia bound $P G-1$ equally ( $\approx 750$ response units). Equal binding was also seen at $20 \mu \mathrm{M}$ PG-1 $(\approx 1000$ response units).

\section{Discussion}

In this study we compared the sensitivity of $P$. aeruginosa and $B$. cepacia strains to protegrin PG-1 with the ability of the intact bacteria and key components of their outer membranes (LPS and lipid A) to bind this peptide. The indices of susceptibility ( $C_{L}$ and MAC values) obtained from our radial diffusion assays established that $P$. aeruginosa was considerably more sensitive to PG-1 than $B$. cepacia. We also found that at any given peptide concentration, many fewer protegrin molecules bound to intact $B$. cepacia and its lipid $A$ than to the corresponding $P$. aeruginosa preparations. In model systems, the ability of protegrins to permeabilize membranes shows pronounced "concentrationgating", an indication that it is influenced by the density of bound protegrin molecules per unit area of membrane [47]. As prior quantitative studies of peptide binding are few in number, some readers may be surprised to note that Fig. 1 shows many millions of protegrin molecules are bound to an average bacterial cell, even at concentrations around the minimal active concentration. To acquire an equivalent density of surface-bound PG-1 molecules, $B$. cepacia needed exposure to much higher concentrations of PG-1 than $P$. aeruginosa. Thus, it is a reasonable inference that the relative resistance of $B$. cepacia to $P G-1$ is a consequence of 


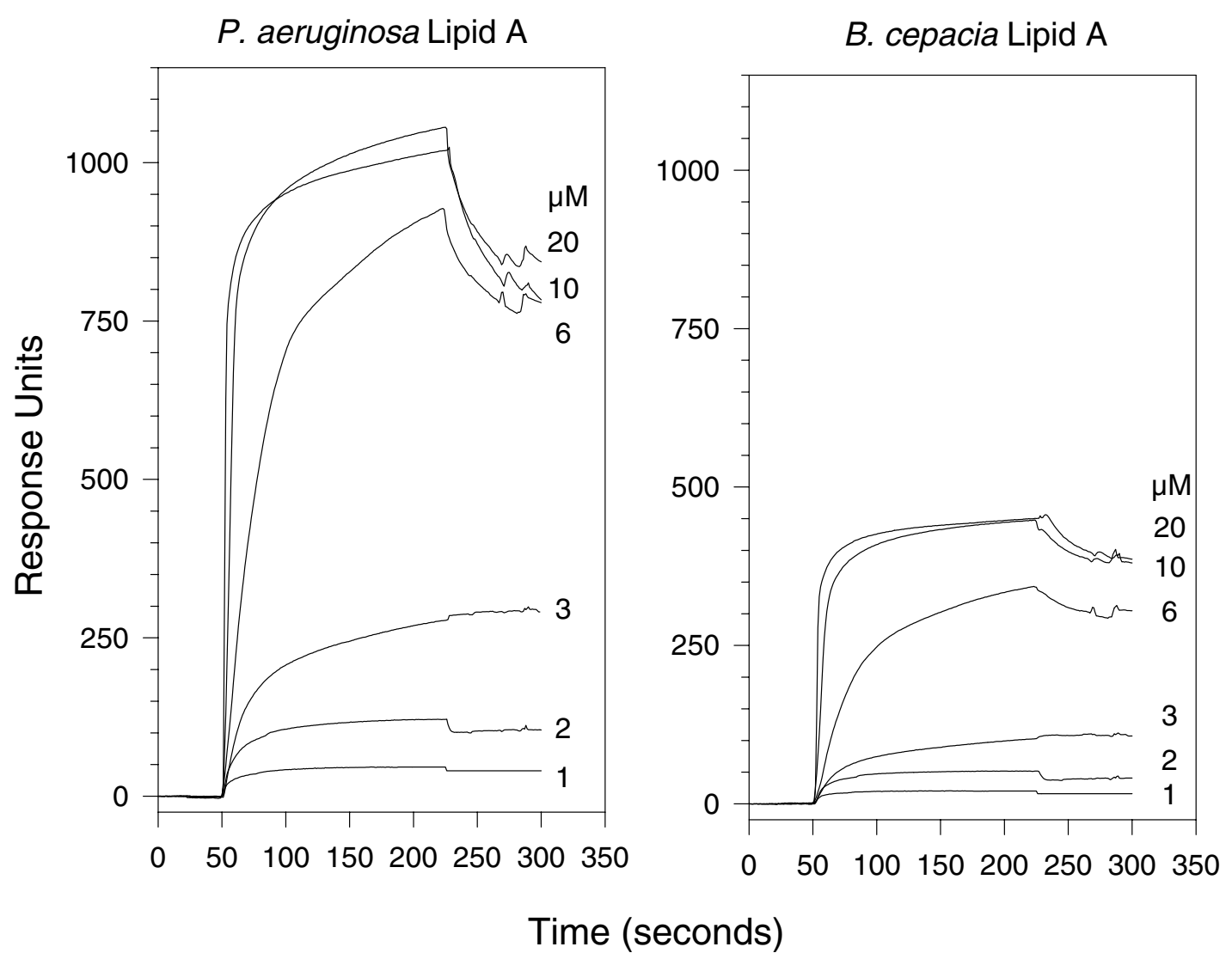

Surface plasmon resonance (SPR) studies of isolated lipid A. PG-1 binding was measured by observing the change in the SPR angle of the sample bound to the chip ( $P$. aeruginosa 9027 lipid A in the left panel, B. cepacia 25416 lipid A in the right panel) as $30 \mu l$ of PG-1 at the indicated concentrations $(1$ to $20 \mu \mathrm{M})$ flowed over the sample. All data points are means $(n=3)$.

the smaller number of protegrin molecules bound per unit area of bacterial surface.

Earlier studies have shown that certain structural differences in the LPS of Gram-negative bacteria correlate with their susceptibility or resistance to antimicrobial (lipo)peptides $[19,23,48-51]$. Particular attention has been given to alterations of the outer membrane that could modify binding to the cell surface. For example, sensitivity to the antibacterial lipopeptide polymyxin B is affected by the PmrA-PmrB regulon, which mediates substitution of 4-aminoarabinose on the $4^{\prime}$ phosphate of lipid A $[52,53]$. By reducing the negative charge of lipid $A$, this modification decreases its electrostatic interaction with cationic peptides. Resistance to polymyxin $B$ is also imparted by the absence or masking of critical binding sites required for polycation-mediated permeabilization of the outer membrane [54]. Thus, attachment of polymyxin $\mathrm{B}$ to Yersinia enterocolitica is reduced by steric hindrance generated by the size and/or branched shape of the outer core region of its LPS macromolecule
[55]. Additionally, resistance to cationic peptides can be due to cytoplasmic clearance of the antimicrobial peptide by an efflux pump; e.g., Yersinia resistance to polymyxin B caused by the RosA/RosB efflux pump/potassium antiporter [56] and Neisseria gonorrhoeae resistance to protegrin PG-1 via an energy-dependent efflux system termed mtr [57].

Given the notorious resistance of $B$. cepacia to conventional antibiotics [2], its relative resistance to PG-1 was not unexpected. What bacterial properties influenced sensitivity to protegrins? Certainly, the striking correlation with the extent of protegrin binding must be one of these. Our studies with genetically related $P$. aeruginosa strains did not implicate the length of the O-antigen side chain as a key factor. Furthermore, genetically related $P$. aeruginosa strains that differed in alginate production were equally sensitive to PG-1. Both results were somewhat surprising, since long $\mathrm{O}$-side chain and alginate molecules should both bind PG1. Perhaps limited alginate production under our experi- 


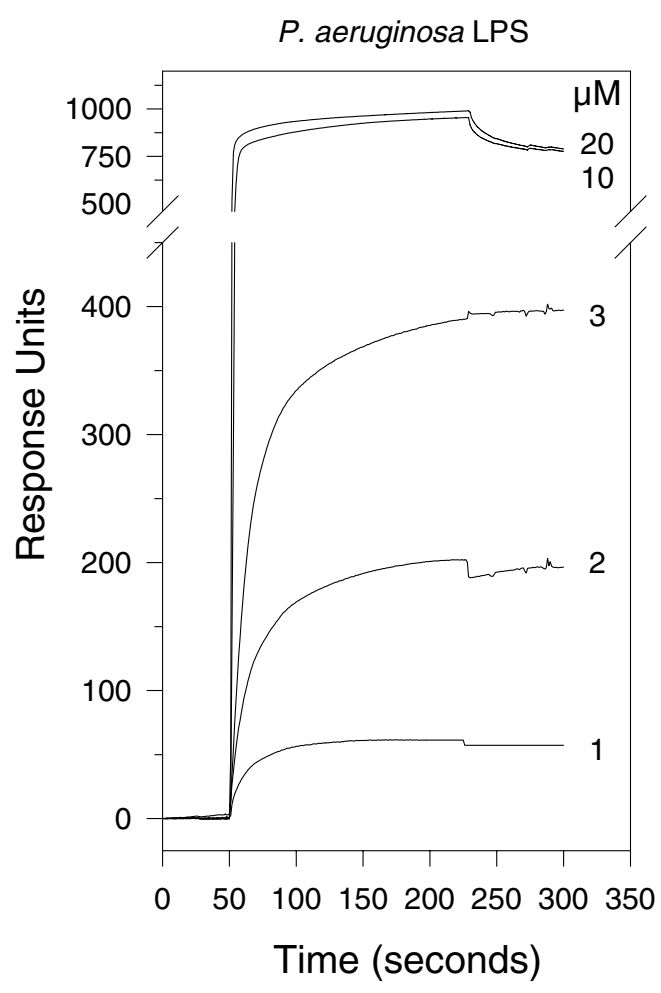

B. cepacia LPS

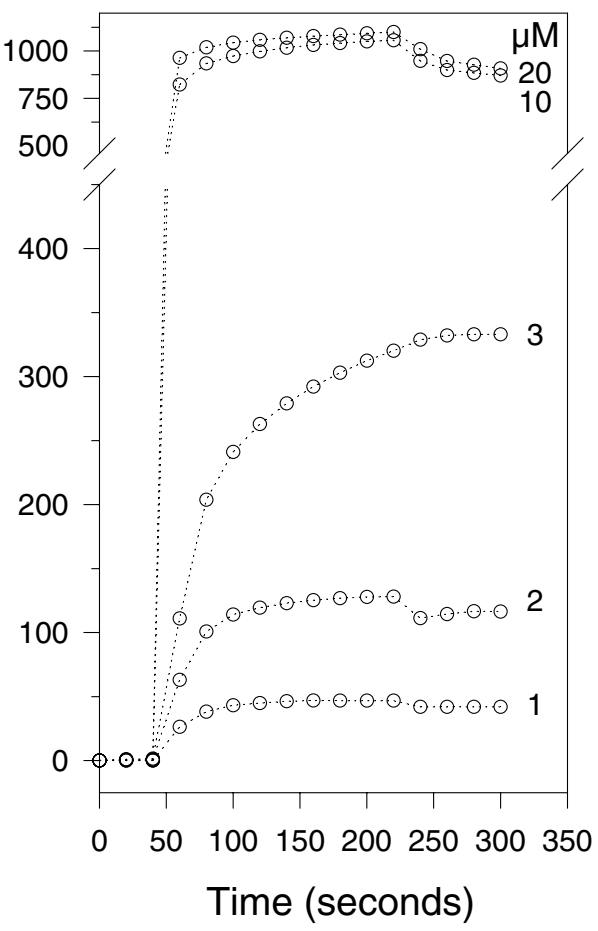

Surface plasmon resonance (SPR) binding studies of isolated LPS. PG-1 binding was measured by observing the change in the SPR angle of the sample bound to the chip ( $P$. aeruginosa 9027 LPS in the left panel, $B$. cepacia 25416 LPS in the right panel) as $30 \mu l$ of PG-1 at the indicated concentrations ( 1 to $20 \mu \mathrm{M})$ flowed over the sample. All data points are means $(n=3)$.

mental conditions explains its failure to influence susceptibility to PG-1. Additional studies focusing on the influence of alginate on PG-1 activity in a biofilm model are in progress.

Why did fewer protegrin molecules bind to $B$. cepacia than to $P$. aeruginosa? Our radial diffusion/binding and SPR studies strongly implicated lipid $A$ as a prime suspect in the case. The acyl chains of lipid A form an integral part of the outer membrane bilayer, and electrostatic or hydrophobic binding of protegrin to lipid A could easily disturb the organization and acyl-chain packing of the outer membrane, both vital in maintaining its integrity and barrier function. Accepting a direct proportionality between measured plasmon resonance $(\mathrm{RU})$ and the extent of peptide bound to the sensor surface, the responses shown in Fig. 4 indicate that at saturation $(20 \mu \mathrm{M})$, lipid $A$ from $B$. cepacia bound almost exactly one-half as many protegrin molecules as lipid $A$ from $P$. aeruginosa. How might this be rationalized?

Lipid A typically contains two phosphate groups, one on each glucosamine residue. In the lipid $A$ of $B$. cepacia, one of these phosphates is modified by a phosphodiesterlinked 4 -amino-4-deoxyarabinose residue $[58,59]$. It is noteworthy that a previous study reported that the phosphate content of $B$. cepacia LPS was only one-third of that of $P$. aeruginosa[60]. If most of the $P$. aeruginosa lipid $A$ phosphates are unmodified, and if these phosphates are principal protegrin binding sites, then one would expect exactly the results shown in Fig. 4. This is also consistent with the suggestion, made in a recent report showing that cystic fibrosis isolates of $P$. aeruginosa had lipid $\mathrm{A}$ isoforms derivatized with aminoarabinose (or palmitate), that these structural modifications could enhance resistance to cationic antimicrobial peptides [61]. Although the acyl chains of lipid A might also provide alternative binding sites for protegrin, the orientation of lipid A on the HPA sensor chip ("butter-side down") probably removes them from consideration, at least under our study conditions.

The core and outer polysaccharide regions of LPS should provide additional binding sites, including the carboxylate moieties of KDO or KO (D-glycero-D-talo-oct-2-ulopyranosylonic acid [62]. This could explain why B. cepacia LPS 
binds about as much PG-1 as $P$. aeruginosa LPS (Fig. 5) especially at peptide concentrations of $10-20 \mu \mathrm{M}$, which allow binding to lower affinity sites. This interpretation helps explain why Fig. 3 suggests that $B$. cepacia LPS binds protegrin less effectively than the corresponding $P$. aeruginosa preparation, while the SPR results in Fig. 5 show that $B$. cepacia and $P$. aeruginosa LPS bound equivalent amounts of PG-1 at high (10-20 $\mu \mathrm{M})$ protegrin concentrations. To resolve these seemingly discrepant results, it is important to recall that in SPR assays, the sensor chips were constantly bathed with a fixed protegrin concentration ranging from 1$20 \mu \mathrm{M}$ and that in radial diffusion assays, the wells received a fixed initial amount of protegrin $(50 \mathrm{ng})$. In the latter assays, the peptide was dispersed in a total volume of $10 \mu \mathrm{l}$, making its maximal initial concentration approximately $2.3 \mu \mathrm{M}$ - well below the $10-20 \mu \mathrm{M}$ concentrations needed to saturate LPS. Moreover, in addition to binding the LPS or lipid A molecules we added to the well, some of the initially added protegrin could diffuse radially into the underlay gel. Both initial binding and radial diffusion will decrease the concentration of free (i.e., unbound) protegrin that remains in the well, and further skew its binding towards higher affinity binding sites on lipid $A$.

Although our data clearly establish the presence of a reduced number of binding sites for protegrin in lipid $A$ from $B$. cepacia, as compared to lipid A from $P$. aeruginosa, they do not identify the cause of this phenomenon. These alterations could result from 4-aminoarabinose substitutions on the lipid A, from other changes that reduce the number of ion-binding sites, or from changes that affect hydrophobic interactions or membrane insertion. Additional studies that characterize $B$. cepacia LPS and lipid A can help pinpoint the exact structural differences that relate to the relative resistance of $B$. cepacia to protegrins and to endogenous antimicrobial peptides of humans.

\section{Conclusion}

Our studies demonstrate a correlation between protegrin sensitivity/resistance and protegrin binding in $P$. aeruginosa and $B$. cepacia, and support a hypothesis that the relative resistance of $B$. cepacia to protegrin is due principally to a reduced number of protegrin binding sites on the lipid A moiety of its LPS.

\section{Abbreviations}

$\mathrm{BSA}=$ bovine serum albumin $\mathrm{CF}=$ cystic fibrosis; $\mathrm{CFTR}=$ cystic fibrosis transmembrane conductance regulator; $C_{L}=$ lethal concentration; $\mathrm{DMSO}=$ dimethyl sulfoxide; $\mathrm{EC}_{50}=$ effective concentration $50 \%$; EDTA = ethylenediamine tetraacetic acid; GGPG = modified PG-1 with a glycine-rich hexapeptide extension (GGGYGG) containing a single tyrosine residue; HEPES $=\mathrm{N}$-2-hydroxyethylpiperazine-N-2-ethanesulfonic acid; HPLC = high performance liquid chromatography; I-GGPG = monoiodinated variant of GGPG; LPS = lipopolysaccharide; MAC = minimal active concentration; $\mathrm{PG}-1=$ protegrin-1; $\mathrm{RU}=$ resonance units; SDS = sodium dodecyl sulfate; SPR $=$ surface plasmon resonance; TSB $=$ trypticase soy broth.

\section{Acknowledgements}

This work was supported in part by grant Al 22389 from National Institutes of Health to RIL and grants from Cystic Fibrosis Research, Inc. to NLS.

\section{References}

1. Drumm ML, Pope HA, Cliff WH, Rommens JM, Marvin SA, Tsui LC, Collins FS, Frizzell RA, Willson JM: Correction of the cystic fibrosis defect in vitro by retrovirus-mediated gene transfer. Cell 1990, 62:1227-1233

2. Govan JRW, Deretic V: Microbial pathogenesis in cystic fibrosis: mucoid Pseudomonas aeruginosa and Burkholderia cepacia. Microbiol Rev 1996, 60:539-574

3. Hutchison ML, Govan JRW: Pathogenicity of microbes associated with cystic fibrosis. Microbes Infect 1999, 1:1005-1014

4. Wine JJ: The genesis of cystic fibrosis lung disease. J Clin Invest 1999, 103:309-312

5. Gilljam H, Ellin A, Strandvik B: Increased bronchial chloride concentration in cystic fibrosis. Scand J Lab Invest 1989, 49:121124

6. Joris L, Dab I, Quinton PM: Elemental composition of human airway surface fluid in healthy and diseased airways. $A m$ Rev Respir Dis 1993, 148:1633-1637

7. Comolli JC, Waite LL, Mostov KE, Engel JN: Pili binding to asialo$\mathrm{GM}_{1}$ on epithelial cells can mediate cytotoxicity or bacterial internalization by Pseudomonas aeruginosa. Infect Immun 1999 , 67:3207-3214

8. Saiman L, Prince A: Pseudomonas aeruginosa pili bind to asialo- $\mathrm{GM}_{1}$ which is increased on the surface of cystic fibrosis epithelial cells. J Clin Invest 1993, 92:1875-1880

9. Pier GB, Grout M, Zaidi TS, Olsen JC, Johnson LG, Yankaskas JR, Goldberg JB: Role of mutant CFTR in hypersusceptibility of cystic fibrosis patients to lung infections. Science 1996, 271:64-67

10. Pier GB, Grout M, Zaidi TS: Cystic fibrosis transmembrane conductance regulator is an epithelial cell receptor for clearance of Pseudomonas aeruginosa from the lung. Proc Natl Acad Sci USA 1997, 94:12088-12093

11. Pier GB: Role of the cystic fibrosis transmembrane conductance regulator in innate immunity to Pseudomonas aeruginosa infections. Proc Natl Acad Sci USA 2000, 97:8822-8828

12. Bals R, Wang X, Wu Z, Freeman T, Bafna V, Zasloff M, Wilson JM: Human $\beta$-defensin 2 is a salt-sensitive peptide antibiotic expressed in human lung. $J$ Clin Invest 1998, 102:874-880

13. Goldman MJ, Anderson M, Stolzenberg ED, Kari UP, Zaasloff M, Wilson JM: Human $\beta$-defensin-1 is a salt-sensitive antibiotic in lung that is inactivated in cystic fibrosis. Cell 1997, 88:553-560

14. Lehrer RI, Lichtenstein AK, Ganz T: Defensins: Antimicrobial and cytotoxic peptides of mammalian cells. Annu Rev Immunol 1993, 11:105-128

15. Wang J, Lory S, Ramphal R, Jin S: Isolation and characterization of Pseudomonas aeruginosa genes inducible by respiratory mucus derived from cystic fibrosis patients. Mol Microbiol 1996, 22:1005-1012

16. Jayaraman S, Joo NS, Reitz B, Wine JJ, Verkman AS: Submucosal gland secretions in airways from cystic fibrosis patients have normal $[\mathrm{Na}+]$ and $\mathrm{pH}$ but elevated viscosity. Proc Natl Acad Sci USA 2001, 98:8119-8123

17. Johnston RB: Clinical aspects of chronic granulomatous disease. Curr Opin Hematol 2001, 8:17-22

18. Speert DP: Understanding Burkholderia cepacia : epidemiology, genomovars, and virulence. Infect Med 2001, 18:49-56

19. Hancock REW, Chappel DS: Peptide Antibiotics. Antimicrob Agents Chemother 1999, 43:1317-1323

20. Kokryakov VN, Harwig SSL, Panyutich EA, Shevchenko AA, Alashina GM, Shamova OV, Korneva HA, Lehrer RI: Protegrins: leukocyte antimicrobial peptides that combine features of corticostatic defensins and tachyplesins. FEBS Lett 1993, 327:231-236 
21. Harwig SSL, Waring AJ, Yang HJ, Cho Y, Tan L, Lehrer Rl: Intramolecular disulfide bonds enhance the antimicrobial and lytic activities of protegrins at physiological sodium chloride concentrations. Eur J Biochem 1996, 240:352-357

22. Steinberg DA, Hurst MA, Fujii CA, Kung AHC, Ho JF, Cheng F-C Loury DJ, Fiddes JC: Protegrin-1: a broad-spectrum, rapidly microbicidal peptide with in vivo activity. Antimicrob Agents Chemother 1997, 41:1738-1742

23. Hancock REW, Lehrer RI: Cationic peptides a new source of antibiotics. Trends Biotech 1998, 16:82-88

24. Yasin B, Lehrer RI, Harwig SSL, Wagar EA: Protegrins: structural requirements for the inactivation of elementary bodies of Chlamydia trachomatis. Infect Immun 1996, 64:4863-4866

25. Qu X-D, Harwig SSL, Shafer WM, Lehrer RI: Protegrin structure and activity against Neisseria gonorrhoea. Infect Immun 1997, 65:636-639

26. Mangoni ME, Aumelas $A$, Charnet $P$, Roumestand $C$, Chiche $L$, Despaux E, Grassy G, Calas B, Chavanieu A: Change in membrane permeability induced by protegrin-1: implication of disulphide bridges for pore formation. FEBS Lett 1996, 383:9398

27. Aumelas A, Magoni M, Roumestand C, Chiche L, Despaux E, Grassy G, Calas B, Chavanieu A: Synthesis and solution structure of the antimicrobial peptide protegrin-1. Eur J Biochem 1996, 237:575-583

28. Fahrner RL, Dieckmann T, Harwig SSL, Lehrer RI, Eisenberg D, Feigon J: Solution structure of protegrin-1, a broad-spectrum antimicrobial peptide from porcine leukocytes. Chemistry Biol 1996, 3:543-550

29. Cho Y, Turner JS, Dinh N-N, Lehrer RI: Activity of protegrins against yeast-phase Candida albicans. Infect Immun 1998, 66:2486-2493

30. Fortney K, Totten PA, Lehrer RI, Spinola SM: Haemophilus ducreyi is susceptible to protegrin. Antimicro Agents Chemoth er 1998, 42:2690-2693

31. Miyasaki KT, Lofel R, Oren A, Huynh T, Lehrer RI: Killing of Fusobacterium nucleatum, Porphyromonas gingivalis and Prevotella intermedia by protegrins. J Periodont Res 1998, 33:91-98

32. Yasin B, Harwig SSL, Lehrer RI, Wagar EA: Susceptibility of Chlamydia trachomatis to protegrins and defensins. Infect Immun 1996, 64:709-713

33. Schiller NL, Hackley DR, Morrison A: Isolation and characterization of serum-resistant strains of Pseudomonas aeruginosa derived from serum-sensitive parental strains. Curr Microbiol 1984, 10:185-190

34. Ohman DE, Chakrabarty AM: Genetic mapping of chromosomal determinants for the production of the exopolysaccharide alginate in a Pseudomonas aeruginosa cystic fibrosis isolate. Infect Immun 1981, 33:142-148

35. Ohman DE, Chakrabarty AM: Utilization of human respiratory secretions by mucoid Pseudomonas aeruginosa of cystic fibrosis origin. Infect Immun 1982, 37:662-669

36. LiPuma JJ, Spilker T, Gill LH, Campbell PW III, Liu L, Mahenthiralingam E: Disproportionate distribution of Burkholderia cepacia complex species and transmissibility markers in cystic fibrosis. Am J Respir Crit Care Med 2001, 164:92-96

37. Steinberg DA, Lehrer RI: Designer assays for antimicrobial peptides: disputing the "one size fits all" theory. Methods in Mol Biol 1997, 78:169-186

38. Lehrer RI, Rosenman M, Harwig SSL, Jackson R, Eisenhauer P: UItrasensitive assays for endogenous antimicrobial polypeptides. J Immunol Methods 1991, 137:167-173

39. Hultmark D, Engstrom A, Andersson $K$, Steiner $H$, Bennich $H$, Boman GH: Insect immunity, attacins, a family of antibacterial proteins from Hyalophora cecropia. EMBO 1983, 2:571-576

40. Hultmark D, Engstrom A, Hennich H, Kapur R, Boman GH: Isolation and structure of cecropin $D$ and four minor antibacterial components from Cecropia pupae. Eur J Biochem 1982, 127:207-217

41. Lehrer RI, Szklarek D, Ganz T, Selsted M: Correlation of the binding of rabbit granulocyte peptides to Candida albicans with candidacidal activity. Infect Immun 1985, 49:207-211

42. Tsomides $\mathrm{T}$, Eisen $\mathrm{H}$ : Stoichiometric labeling of peptides by iodination of tyrosyl or histidyl residues. Anal Biochem 1993, 210:129-135

43. Darveau RP, Hancock REW: Procedure for isolation of bacterial lipopolysaccharides from both smooth and rough Pseu- domonas aeruginosa and Salmonella typhimurium strains. $J$ Bacteriol 1983, 155:831-838

44. Mattsby-Baltzer I, Kaijser B: Lipid A and anti-lipid A. Infect Immun 1979, 23:758-763

45. Qureshi N, Takayama K: Purification and structural determination of nontoxic lipid $A$ obtained from the lipopolysaccharide of Salmonella typhimurium. J Biol Chem 1982, 257:11808-11815

46. Tan NS, Ng ML, Yau YH, Chong PK, Ho B, Ding JL: Definition of endotoxin binding sites in horseshoe crab factor $C$ recombinant sushi proteins and neutralization of endotoxin by sushi peptides. FASEB J. 2000, 14:1801-1813

47. Heller WT, Waring AJ, Lehrer RI, Harroun TA, Weiss TM, Yang $L$, Huang HW: Membrane thinning effect of the $\beta$-sheet antimicrobial protegrin. Biochem 2000, 39:139-145

48. Freer E, Moreno E, Moriyon I, Pizarro-Cerda J, Weintraub A, Gorve $\mathrm{J}$-P: Brucella-salmonella lipopolysaccharide chimeras are less permeable to hydrophobic probes and more sensitive to cationic peptides and EDTA than are their native Brucella sp. counterparts. J Bacteriol 1996, 178:5867-5876

49. Hancock REW, Bell A: Antibiotic uptake into Gram-negative bacteria. Eur J Clin Microbiol Infect Dis 1988, 7:713-720

50. Martinez de Tejada G, Pizarro-Cerada J, Moreno E, Moriyon I: The outer membranes of Brucella spp. are resistant to bactericidal cationic peptides. Infect Immun 1995, 63:3054-3061

51. Piers KL, Brown MH, Hancock REW: Improvement of outer membrane-permeabilizing and lipopolysaccharide-binding activities of an antimicrobial cationic peptide by C-terminal modification. Antimicrob Agents Chemother 1994, 38:2311. 2316

52. Gunn JS, Ryan SS, Van Velkinburgh JC, Ernest RK, Miller SI: Genetic and functional analysis of a PmrA-PmrB-regulated locus necessary for lipopolysaccharide modification, antimicrobial peptide resistance, and oral virulence of Salmonella enterica serovar typhimurium. Infect Immun 2000, 68:6139-6146

53. Gunn JS, Lim KB, Krueger J, Kim K, Guo L, Hackett M, Miller SI: PmrA-PmrB-regulated genes necessary for 4-aminoarabinose lipid A modification and polymyxin resistance. Mol Microbiol 1998, 27:1171-1182

54. Moore RA, Hancock REW: Involvement of outer membrane of Pseudomonas cepacia in aminoglycoside and polymyxin resistance. Antimicrob Agents Chemother 1986, 30:923-926

55. Skurnik M, Venho R, Bengoechea JA, Moriyon I: The lipopolysaccharide outer core of Yersinia enterocolitica serotype 0:3 is required for virulence and plays a role in outer membrane integrity. Mol Microbiol 1999, 31:1443-1462

56. Bengoechea JA, Skurnik $M$ : Temperature-regulated efflux pump/potassium antiporter system mediates resistance to cationic antimicrobial peptides in Yersinia. Mol Microbiol 2000 37:67-80

57. Shafer WM, Qu X, Waring AJ, Lehrer Rl: Modulation of Neisseria gonorrhoeae susceptibility to vertebrate antibacterial peptides due to a member of the resistance/modulation/division efflux pump family. Proc Natl Acad Sci U S A 1998, 95:1829-1833

58. Cox $A D$, Wilkinson $S G$ : lonizing groups in lipopolysaccharides of Pseudomonas cepacia in relation to antibiotic resistance. Mol Microbiol 1991, 5:641-646

59. Gunn JS, McCoy AJ, Tran L, Liu H, Falla T: Identification and characterization of Burkholderia cepacia mutants sensitive to antimicrobial peptides, abstr A92, p. 22 In Abstracts of the American Society for Microbiology: 101st General Meeting 2001, abstr A92:22

60. Manniello JM, Heymann H, Adair FW: Isolation of atypical lipopolysaccharides from purified cell walls of Pseudomonas cepacia. J Gen Microbiol 1979, 29:496-500

61. Ernst RK, Yi EC, Guo L, Lim KB, Burns JL, Hackett M, Miller SI: Specific lipopolysaccharide found in cystic fibrosis airway Pseudomonas aeruginosa. Science 1999, 286:1561-1565

62. Wimmera N, Bradeb H, Kosma P: Synthesis of neoglycoproteins containing D-glycero-D-talo-oct-2-ulopyranosylonic acid (KO) ligands corresponding to core units from Burkholderia and Acinetobacter lipopolysaccharide. Carb Res 2000, 329:549560 